\title{
PEDAGOGIAS DAS BOAS MANEIRAS: FORMANDO CIDADÃOS CIVILIZADOS E HIGIÊNICOS ${ }^{1}$
}

DOI: http://dx.doi.org/10.1590/2236-3459/69601

\author{
Maria Angélica Zubaran \\ Juliana Ribeiro de Vargas \\ Universidade Luterana do Brasil (Ulbra), Canoas/Rio Grande do Sul, Brasil
}

$\cos 80$

\begin{abstract}
Resumo
A presente pesquisa investiga as narrativas da coluna Da Educação, veiculadas no jornal de imprensa negra O Exemplo (1892-1930), entre 1916 e 1917, na cidade de Porto Alegre (RS), na perspectiva teórica dos Estudos Culturais e da História da Educação. O objetivo central desse estudo é discutir e problematizar o potencial pedagógico dessa mídia impressa, analisando como essas narrativas buscaram educar a comunidade negra no período pós-abolição. Entre os resultados, destaca-se que narrativas normativas, disseminaram regras de conduta e de comportamento, "pedagogias das boas maneiras", que deveriam ser seguidas pelos negros (as), em diferentes espaços sociais, visando reeducá-los e torná-los cidadãos civilizados e higiênicos, a fim de melhor integrá-los na sociedade brasileira da época.

Palavras-chave: imprensa negra, pedagogias, história da educação, civilidade.
\end{abstract}

\section{PEDAGOGIES OF GOOD MANNERS: FORMING CITIZENS CIVILIZED AND HYGIENICS}

\begin{abstract}
The present research investigates the narratives of the column Da Educação (On Education), published in the black press $O$ Exemplo (1892-1930), between 1917, in the city of Porto Alegre (RS), from the theoretical perspective of Cultural Studies and History of Education. The central objective of the study is to discuss and problematize the pedagogical potential of this printed media, analyzing how these narratives sought to educate the black community in the post-abolition period. Among the results, it should be noted that the normative narratives produced in this column were based on the manuals of civility and in the medical-hygienist and positivist discourses that circulated in Brazil between the end of the 19th century and the beginning of the 20th century. Based on these premises, these normative narratives disseminated rules of conduct and behavior, "pedagogies of good manners", that black people should follow in different social spaces, with the aim of reeducating them and making them civilized and hygienic citizens, in order to better integrate them into the Brazilian society of the time.

Keywords: black press, pedagogies, history of education, civility.
\end{abstract}

\footnotetext{
${ }^{1}$ A pesquisa que resultou neste artigo contou com o auxílio dos seguintes bolsistas de Iniciação Científica: Thanise Guerine Atolini, Jéssica Lein e Vitor Costa.
} 


\title{
PEDAGOGÍA DE LAS BUENAS COSTUMBRES: FORMANDO CIUDADANOS CIVILIZADOS Y HIGIÉNICOS
}

\begin{abstract}
Resumen
La presente pesquisa investiga las narrativas de la coluna Da Educação (De la Educación), vehículadas en el periódico de la prensa negra O Exemplo (1892-1930) entre 1916 e 1917, en Porto Alegre (RS), desde la perspectiva teórica de los Estudios Culturales y de la História de la Educación. El objetivo principal del estudio es discutir y problematizar el potencial pedagógico de este medio impreso, analisando cómo estas narrativas trataron de educar a la comunidad negra en el período posterior à la abolición. Entre los resultados, se ressalta que narrativas normativas difundiran reglas de conducta y comportamiento, "pedagogías de buenas maneras", que deberian ser seguidas por los negros (as) en espacios sociales distintos, con el objetivo de reeducarlos y hacerlos ciudadanos civilizados y higiénicos, para mejor integrarlos en la sociedad brasileña de la época.

Palabras clave: prensa negra, pedagogías, história de la educación, civilidad.
\end{abstract}

\section{PEDAGOGIE DES BONNES MANIERES: LA FORMATION DES CITOYENS CIVILISES ET HYGIENIQUES}

\section{Résumé}

Notre recherche étudie les récits de la section Da Educação (De l'Éducation), publiés en 1917 à Porto Alegre (RS) dans le journal de la presse noire O Exemplo (1892-1930), à travers le prisme théorique des Études Culturelles et de l'Histoire de l'Éducation. L'objectif principal de notre étude est d'examiner le potentiel pédagogique de cette presse et d'analyser la façon dont ces récits cherchaient à éduquer la communauté noire dans la période post-abolition. Parmi les résultats, soulignons que ces récits ont disseminé des règles de conduite et de comportement, des "pédagogies des bonnes manières" qui devaient être suivies par les noir(e)s dans les différents espaces sociaux. Ces règles avaient pour but de les rééduquer et les transformer en citoyens civilisés et hygiéniques afin de mieux les intégrer à la société brésilienne de l'époque.

Mots-clés: presse noire, pédagogies, histoire de l'éducation, civilité. 


\section{Introdução}

$\mathrm{N}$ este estudo, analisamos as narrativas produzidas na coluna intitulada $\mathrm{Da}$ Educação, veiculadas na primeira página do jornal $O$ Exemplo, nos anos de 1916 e 1917. Investiga-se o potencial pedagógico deste jornal da imprensa negra, examinando-se como produziu e disseminou "pedagogias das boas maneiras", na tentativa de educar negros e negras, de acordo com os padrões das regras de civilidade europeias e os discursos médico-higienistas, que circulavam na maior parte das capitais brasileiras entre o final do século XIX e primeiras décadas do século XX.

O presente artigo vincula-se às perspectivas teóricas dos Estudos Culturais e da História da Educação. Considera-se que é na cultura e na linguagem que se produzem discursivamente padrões de conduta e de comportamento, normatizando-se e elegendo-se como parâmetro determinados modelos e identidades que se apresentam como naturais e ideais para todos. Esse processo se constitui como uma das formas mais sutis de manifestação do poder no campo da identidade e da diferença. É neste contexto da produção de identidades e diferenças e das disputas políticas pelo reconhecimento das identidades negras, que se entende a construção de estratégias pedagógicas no jornal $O$ Exemplo. Portanto, analisa-se este periódico como um artefato cultural que produz e faz circular pedagogias, e que está envolvido em processos de construção de subjetividades e de identidades negras, destacando-se, particularmente, as pedagogias acionadas na coluna Da Educação.

Conforme destacam Maria Helena Câmara Bastos (2002) e Wenceslau Gonçalves Neto (2002), nos últimos anos a imprensa vem sendo utilizada como uma fonte documental valiosíssima para a compreensão da História da Educação. Para Gonçalves Neto, a imprensa funciona como um veículo educativo que divulga e consolida as principais representações sociais de uma época. Já André Mazini (2012) destaca que as pesquisas sobre a imprensa, enquanto fonte de investigação, ganharam amplitude, particularmente, nas análises produzidas sob o viés teórico da História Cultural e "com recorte temporal a partir do século XIX, período em que os jornais apresentavam suas leituras sobre os acontecimentos sociais, evidentemente com diferentes níveis de comprometimento político, econômico e ideológico". (MAZINI, 2012, p. 3). Segundo Pasquini e Toledo (2014), nas últimas duas décadas, se ampliou no Brasil o número de estudos históricos sobre a educação relacionados à imprensa periódica ou pedagógica. De acordo com esses autores, o uso da imprensa traz inscrita em suas páginas elementos históricos que proporcionam o entendimento não só do processo educacional em si, mas dos debates havidos na sociedade e desempenham papel relevante nesta área do conhecimento. Nessa perspectiva, esses pesquisadores salientam que é a própria vida cotidiana que é registrada nas páginas dos periódicos, inclusive os passos e obras dos cidadãos menos favorecidos, a exemplo da comunidade negra de Porto Alegre no jornal $O$ Exemplo.

Por outro lado, conforme Tomaz Tadeu da Silva (2014, p. 140), é o conceito de pedagogia que permite pensar a imprensa como uma instância pedagógica, que como "outras instâncias culturais também ensinam coisas". Nesta perspectiva, Camozzato, Carvalho e Andrade (2016, p. 9) salientam que "as histórias do conceito de pedagogia nos mostram que se trata, especialmente, de compreender que a pedagogia está intensamente relacionada com a condução e a fabricação de modos de ser e viver". A partir destas considerações, entende-se que já no início do século $\mathrm{XX}$, pode-se mapear na imprensa 
negra uma multiplicidade de pedagogias em atividade, que se manifestam nos esforços contínuos dos intelectuais negros para conduzir e "dar forma" aos sujeitos da comunidade negra porto-alegrense e de atuar em vários âmbitos de suas vidas.

O jornal O Exemplo apareceu em Porto Alegre, em 11 de dezembro de 1892, como "Propriedade de uma Associação", que, segundo estudos realizados por Liane Müller (2013), estava relacionada à Irmandade de Nossa Senhora do Rosário, mais especificamente, ao fato de alguns de seus fundadores terem sido membros desta Irmandade, caso de Aurélio Veríssimo de Bittencourt e de Calisto Felizardo de Araújo. O jornal foi fundado por um grupo de jovens negros, "moços esperançosos e ávidos de justiça", que costumavam reunir-se em uma barbearia, o Salão Calisto, situado à Rua dos Andradas no. 247, no centro da cidade de Porto Alegre. Entre seus fundadores destacamse: Arthur de Andrade (diretor de redação), Marcílio Freitas (editor gerente), os irmãos Aurélio Bittencourt Júnior e Sérgio Bittencourt, os irmãos Esperidião Calisto e Florêncio Calisto, entre outros. Era um jornal semanal, de quatro páginas, três colunas, formato 30x21, que saía aos domingos, de tiragem modesta, vendido pelos próprios editores, na sede do jornal, ou através de assinaturas semestrais. O jornal possuía representantes no Rio de Janeiro e em várias cidades do interior do Rio Grande do Sul, entre elas: Rio Grande, Pelotas, Rio Pardo, Cachoeira, Santa Cruz, Barra do Ribeiro, Encantado, Taquara, Santa Maria, Bom Jesus, Alegrete, São Sepé, Caxias, São Leopoldo. (O EXEMPLO, 07/05/1916, p. 1). De acordo com John D. H. Downing (2004), considera-se o jornal O Exemplo como uma mídia radical, cujo modelo de organização enquadra-se na tradição da autogestão, pois não estava nas mãos nem de partidos, nem de sindicatos, nem de um proprietário, mas se apresentava como sendo propriedade de uma associação. Era um jornal de pequena escala, uma mídia de minoria étnica, que apresentava conteúdos assertivos, de denúncia de preconceitos raciais e de abusos racistas e que buscava educar e promover a autoestima de negros (as) em Porto Alegre, entre o final do século XIX e as primeiras décadas do século XX.

Destaca-se também, que as narrativas da coluna Da Educação publicadas na primeira página do jornal, entre os anos de 1916 e 1917, remetem aos chamados "manuais de civilidade", um conjunto de obras que foram sucesso editorial na Europa, desde o século XVI e XVII, na transição da Idade Média para a Idade Moderna, que buscou disciplinar comportamentos sociais, prescrevendo modelos e condenando condutas consideradas "impróprias".

O sociólogo Norbert Elias (1989), na obra O Processo Civilizador², analisou a chamada literatura de civilidade, particularmente, as obras de Erasmo de Rotterdam, A Civilidade Pueril, de 1530, e a de São João Batista de La Salle, Regras do Decoro e da Civilidade Cristã, de 1651, produzidas e difundidas, sobretudo na França, nos Países Baixos e na Alemanha. Segundo o autor, estas sociedades atravessavam uma "complexidade mais acentuada das relações entre grupos diversificados" e precisavam "de uma linguagem comum e de novos pontos de referência" de como comportarem-se socialmente. Como salienta Elias, os manuais eram signos de refinamento e hierarquia entre os indivíduos, definindo como ser civilizado, polido, educado.

2 O Processo Civilizador foi publicado no Brasil em dois volumes: o primeiro volume, Uma História dos Costumes e o segundo, A Formação do Estado e a Civilização. 
A regulamentação minuciosa da etiqueta, do cerimonial, do gosto, do modo de vestir e mesmo do modo de falar e de portar-se, tinha a mesma função. Cada pormenor era uma arma na luta pelo prestígio. A regulamentação não visava apenas a representação exterior marcava mentalmente as distâncias que separavam uns e outros. (ELIAS, 1989, p. 86).

Também Jacques Revel (1991), ao analisar a literatura de civilidade, destacou que essas obras codificavam e regulavam os comportamentos sociais nas principais circunstâncias da vida em sociedade e proclamavam que "as manifestações do corpo gestos, mímicas, atitudes - constituíam expressões legíveis do homem interior e revelavam as disposições da alma". (p. 172). Para o referido autor, ao regulamentarem os gestos e manifestações do corpo, esses manuais pretenderam formar e reformar o cidadão moderno. Assim, seriam proscritos "os gestos e atitudes que poderiam arrancar a humanidade de si mesma e arrastá-la para a animalidade", por exemplo, "o riso equino e a voz nasal que lembra o elefante [...]". (p. 175). Conforme Revel, o destino das civilidades perduraria muito além deste período de transição, com adaptações e práticas renovadas como veremos a seguir também na imprensa negra.

Em Portugal, destacou-se no século XIX, o Código do Bom-Tom ou Regras da Civilidade e de Bem Viver no século XIX, de autoria do cônego José Inácio Roquette, publicado no ano de 1845. Lilia M. Schwarcz, na introdução ao livro, argumenta que o Código do Bom-Tom ganhou leitores fiéis entre a aristocracia brasileira imperial "quase selvagem e distante dos grandes centros". (SCHWARCZ, 1997, p. 16). Segundo Schwarcz, "o princípio de hierarquia que orienta todo o livro esconde a desigualdade social sob o manto de uma naturalidade quase biológica e joga as diferenças para o plano do costume" (ibidem, p. 20). O guia regulava e normatizava o comportamento social nos mais diferentes espaços: na igreja, nos batizados e casamentos, nas festas e enterros.

Quando o Código de Roquette começou a circular no Brasil, na primeira metade do século XIX, as principais cidades brasileiras estavam ainda se desenvolvendo e as elites precisavam de modelos de comportamento para conviver socialmente e o modelo de civilidade adotado foi o francês, base do Código do Bom-Tom. Conforme aponta Schwarcz: "diante de uma realeza isolada, em meio às demais repúblicas americanas, de um império escravocrata que dissimulava as marcas dessa instituição e de uma nobreza brasileira recém-criada, tais guias foram recebidos com entusiasmo". (ibidem, p. 29).

Por outro lado, não se pode ignorar que, logo após a abolição da escravidão e a proclamação da República, as elites brasileiras pretendiam tornar o país uma nação moderna e branca. Neste contexto, como argumentou Amanda Braga (2015, p. 85), a imprensa negra e as sociedades negras recreativas e culturais buscavam "reeducar a raça" contra os estereótipos consagrados ao negro nos séculos anteriores, fomentado por teorias "racistas que circulavam em meio à intelectualidade brasileira, maciçamente, a partir da segunda metade do século XIX". (ALMEIDA; ALVES, 2011, p. 86). Foi provavelmente com esta intenção, de reeducar a comunidade negra, que o jornal $O$ Exemplo veiculou durante o ano de 1917, a coluna Da Educação, por meio da qual, apelava à civilidade e à higiene, para conter e normatizar o comportamento social da comunidade negra de Porto Alegre. Braga argumenta que: 
Era preciso promover uma segunda abolição, uma vez que aquela anunciada em 1888 não oferecia ao negro mais do que uma vida de privações (...). Era preciso, inserir esse negro no mercado de trabalho, no sistema educacional, na atividade política e, por fim, contestar, em definitivo, a associação feita entre a imagem do negro e sua eterna condição de escravo, ratificada por uma suposta inferioridade congênita. (BRAGA, 2015, p. 87).

Segundo a autora, fazia-se o uso de atributos ligados ao "caráter, à educação, aos bons costumes, "para mostrar certa evolução do homem negro" e para "reformulá-lo, livrando-o de todos os "vícios" adquiridos no decorrer do período escravocrata". A autora afirma ainda que:

[...] esse discurso estava ligado à recusa de uma memória que trabalhava na manutenção de uma série de estereótipos ligados ao negro: a indolência, a preguiça, a criminalidade, o deboche, a falta de iniciativa. Contra todos esses estereótipos, era na educação - formal, política, cultural - que se apostava. (BRAGA, 2015, p. 89).

Possivelmente, os redatores do jornal encontraram no formato dos manuais de civilidade uma maneira para promover uma reeducação normativa de negros (as) em Porto Alegre no pós-abolição.

Na História da Educação, os manuais de civilidade foram analisados nos estudos de: Maria Stephanou (2004), Maria Teresa Cunha (2005), Cristiane Cecchin (2007), Divania Rodrigues e Paula Marroni (2012). Maria Stephanou (2004) destacou a relação entre a constituição do sujeito urbano e os discursos médicos presentes em manuais de saúde, entre os anos de 1930 e 1940. A autora argumenta que os manuais pretendiam "ensinar à cada um como melhor se conduzir com vistas à polidez e a civilidade, refreando instintos que lembravam a animalidade e cultivando modos de ser agradáveis a si mesmos e aos outros" (STEPHANOU, 2004, p. 2). Ela analisou, particularmente, dois manuais escritos pelo médico gaúcho Mário Totta, que tiveram muitas reedições entre os anos de 1930 e 1940. Esses manuais de saúde interpelaram homens e mulheres a observar cuidadosamente a saúde e a higiene, concebidas como virtudes modernas que tornariam possível a convivência urbana. (ibidem, p. 3).

Já Maria Teresa Cunha (2005, p. 7) analisou manuais de civilidade nas décadas de 1920 e 1930 e destacou o uso desses manuais no espaço da Escola Normal, "como parte dos materiais didáticos utilizados nas aulas de civilidade previstas nos currículos das Escolas Normais" na primeira metade do século XX. A autora destaca que as prescrições de etiqueta e civilidade estavam endereçadas aos professores e contribuíram para difundir tais práticas entre seus alunos (as), disciplinando suas maneiras e gestos.

Também Cristiane Cecchin e Maria Teresa Cunha, (2007, p. 4) ao estudarem um corpus documental de manuais de civilidade, afirmam que "a literatura de civilidade difundida pelos manuais no Brasil, criou possibilidades para a circulação de práticas de urbanidade e propiciou uma forma de educação pela leitura entre jovens e adultos nas cidades". Para as autoras, "o intuito era normatizar comportamentos, internalizar regras e preceitos para a formação do bom cidadão, bem como para contribuir para a formação do caráter e das práticas de higiene", que se firmavam no cotidiano das grandes cidades (CECCHIN; CUNHA, 2007, p. 6).

Acrescenta-se ainda, o estudo de Divania Luiza Rodrigues e Paula Carolina Marroni 
(2012), que a partir da análise do Manual de Civilidade Pueril de Erasmo de Rotterdam e do Processo Civilizador de Norbert Elias, refletiram sobre o conceito de civilidade e suas implicações históricas para o contexto educacional, considerando a civilidade como uma pedagogia do comportamento, que, no século XVI, expressou "um modo de educar crianças e jovens". (RODRIGUES; MARRONI, 2012, p. 13).

No presente estudo, considera-se a influência dos manuais de civilidade e dos discursos médico-higienista e positivista na imprensa negra, particularmente, no jornal $O$ Exemplo, com o propósito de reeducar a comunidade negra de Porto Alegre, nas primeiras décadas do século XX. Vale destacar que regras de conduta e de boas maneiras também foram discutidas em outros espaços do jornal, sob os seguintes títulos: uma esposa correta, arrependido de ter casado, costumes depravados, os oito mandamentos do marido exemplar, como se deve comer, e palavras e frases vulgares, que demonstram que este era um tema particularmente importante para o jornal.

Conforme afirma Sérgio Alfredo Guimarães (2002, p. 92), no pós-abolição "reeducar a massa negra significava ao mesmo tempo distanciar-se dela". Também na coluna Da Educação, tratava-se de regulamentar as condutas sociais de negros (as), prescrevendo atitudes e comportamentos, de acordo com padrões europeus e regras de higiene consideradas pelo discurso médico como necessárias para a convivência em diferentes espaços sociais. Por outro lado, essas narrativas condenavam como "impróprios, "malévolos", "insolentes" e de "péssima educação" aqueles hábitos que não se enquadravam nas regras prescritas. Vejamos a seguir.

\section{A Coluna Da Educação: regulando comportamentos}

De acordo com a classificação de Marques de Melo (2016), considera-se que coluna é um formato jornalístico pertencente ao gênero opinativo que inclui textos nos quais são expostos pontos de vista acerca de algo. Segundo o autor, do gênero jornalístico opinativo também fazem parte os editoriais, artigos, cartas e crônicas. ${ }^{3}$ Nesta pesquisa, mapeamos um total de trinta colunas denominadas Da Educação, no jornal O Exemplo. Essas colunas estão organizadas em subtítulos temáticos, que se referem a diferentes espaços de convivência social, tais como: a família, o colégio, os lugares públicos, as visitas, a conversação em geral, dos vícios e defeitos na conversação, do gracejo, da controvérsia, as fórmulas de tratamento, nos bailes, da comida em geral, dos banquetes ou jantares e cerimônias e nas correspondências epistolares.

Uma primeira aproximação das narrativas da coluna Da Educação revela a importância dada à família na educação da comunidade negra de Porto Alegre. Sob o subtítulo $A$ família, destaca-se a seguinte declaração: "a família é a célula mater da sociedade", onde "o indivíduo deve haurir seus primeiros ensinamentos" e onde "o bom filho será o melhor cidadão" (O EXEMPLO, 18/03/1917, p. 1, № 12), disseminando a ideia da função social do grupo familiar e de que cabia à família contribuir para a construção do povo brasileiro. De acordo com Jurandir Freire Costa (1983, p. 63), "a família projetada pelos higienistas, deixar-se-ia manipular, acreditando-se respeitada, e autorregular-se-ia, tornando cada um dos seus membros um agente da saúde e de uma nova moral a serviço

3 Destaca-se que a coluna Da Educação não traz a assinatura de um autor, representando, portanto, um posicionamento do jornal. 
do Estado". Nesta direção, Marcus J. M. Carvalho (2006) chamou atenção para a propagação de um discurso sobre a família oitocentista, em que a família civilizada se tornaria um microcosmos da pátria.

Por outro lado, Iranilson Buriti de Oliveira (2011, p. 4), destaca que "a família tradicional afeita ainda aos códigos coloniais nas cidades oitocentistas ia sendo afetada, impactada pela emergência de novos hábitos e equipamentos, distanciando-se de seus antigos valores". Também no jornal O Exemplo, na coluna Da Educação, pai e mãe tinham seus papéis bem regulados, aos homens designava-se o trabalho externo, enquanto que o papel da mulher era, mais uma vez, o da "a genitora do lar", que "por ser um espírito mais terno e complacente" melhor exercitaria a "missão" de cuidar dos filhos e de manter a família. Assim manifestavam-se os redatores:

\footnotetext{
Na direção e doutrinação do pequeno a genitora do lar tem o papel proeminente por ser nele onde a plenitude de sua autoridade se exercita de uma maneira mais nobre e respeitosa. Pelo papel desempenhado no lar pela mulher chegou o poeta a dizer que a mulher é uma rainha e que seu trono é o lar. Também a mulher por ser um espírito mais terno e complacente essa missão entregue aos seus desvelos é muito melhor exercida. (O EXEMPLO, Da Educação, 18/03/1917, p. 1).
}

Portanto, pode-se dizer que a coluna Da Educação reforçava os papéis tradicionais de homens e mulheres no intuito de preservar a família nuclear estável e de se contrapor à imagem estereotipada da "família negra desorganizada", que circulava na grande mídia.

A segunda coluna publicada, sob o subtítulo $O$ Colégio, demonstrava que a organização das colunas não era aleatória, mas que seguia uma hierarquia de espaços educativos, que começava na família, continuava no colégio, considerado espaço de aprimoramento da "educação recebida no lar", e daí seguia, com suas prescrições e normas, para os "lugares públicos". Observa-se também que, sempre que possível, essas narrativas buscavam construir comportamentos que contrariassem os estereótipos geralmente atribuídos aos negros. No espaço social do colégio, recomendava-se aos pais evitarem a ausência de seus filhos na escola, afirmando-se que "nem sempre a criança gazeava a aula por preguiça". Desta forma, os redatores se contrapunham ao estereótipo da preguiça frequentemente atribuído aos negros e, por extensão, às crianças negras, reminiscências dos estigmas da escravidão, que persistiam na sociedade brasileira do início do século $X X$.

Já a coluna cujo subtítulo era Os lugares públicos referia-se às regras de convivência social nos cinemas e cineteatros. De acordo com Sérgio da Costa Franco (1988), as primeiras salas de cinema de Porto Alegre, no início do século XX, eram três: Cinema Variedades, na esquina dos Andradas com a Praça da Alfândega; o Smart Salão, no piso térreo do Grande Hotel, situado à Rua dos Andradas e o Recreio Ideal, na Praça da Alfândega, também no centro da cidade. Em 1910, inaugurava-se o Coliseu, que evoluiu para cineteatro. Segundo o autor, também na categoria de cineteatro, foram abertos ao público em 1913, o Guarani, com 958 lugares, e em 1914, o cineteatro Apolo, com mais de dois mil lugares. Franco descreve ainda que "em 1935, quando a população urbana de Porto Alegre andava em torno de 250 mil habitantes, a cidade possuía 22 cinemas". De fato, como comenta o autor, nas primeiras décadas do século XX, o cinema se transformou em uma "coqueluche local". (FRANCO, 1988, p. 115). Nestes cineteatros, além do filme, apresentava-se também a orquestra. A coluna Da Educação assim se manifestava: 
É preciso que se saiba que nem todos vão aos cines pura e simplesmente para ver filmes. Pessoas há de fato que lá vão só para ver filmes; outros vão para gozar da melodia da orquestra, e outras para gozar da beleza do filme e orquestra conjuntamente. Se um importuno começa a emitir parecer em voz alta, interrompe a atenção dos que não se podem furtar ao prazer de ouvir os acordes da orquestra acompanhando a passagem do filme. Outra grosseria chata é a de acompanhar com estalos e chiados as cenas cinematográficas em que há passagens onde os personagens trocam beijos. (O EXEMPLO, Da Educação, 01/04/1917, p. 1).

Neste contexto, a imprensa negra assumia a tarefa de reeducar negros e negras para o convívio nestes novos espaços de sociabilidade, em que se recomendava, entre outras coisas, "não falar alto", "não sentar nos braços das poltronas" e "não fumar".

Em matéria intitulada Costumes depravados, os articulistas do jornal repreendiam com veemência o comportamento de espectadores em um espetáculo da Sociedade dramática Grêmio Dramático Carlos Gomes, realizada no salão da Sociedade Floresta Aurora 4 , que "sentados sobre o encosto da cadeira e com os pés sobre o assento" ou "com os chapéus na cabeça, no recinto onde se realizava o espetáculo" ou ainda, que "conversam em altas vozes" e concluíam: "o que isto atesta é a falta de civilidade de certos mocinhos que, exteriormente, apresentam-se com modos de boas pessoas. Por fora, corda de viola, por dentro pão bolorento". (O EXEMPLO, 08/07/1917, p. 1). É interessante que, na conclusão da matéria, o articulista do jornal declarava que: "era para esses mocinhos" que o jornal recomendava "a leitura da série de artigos que sobre a Educação vem sendo editados por esta folha”, demonstrando que as intenções pedagógicas explicitas das colunas Da Educação. Por outro lado, a matéria demonstrava também a produção de atividades culturais e educativas nas sociedades negras e a participação da comunidade negra nestas atividades culturais. Neste sentido, são várias as referências às sociedades negras dramáticas no jornal $O$ Exemplo, destacando-se entre elas: a Sociedade Dramática Floresta Aurora (1917), a Sociedade Dramática Carlos Gomes (1916), o Euterp Club (1917), o Grêmio Literário e Dramático Arthur Rocha (1916). Muitas das peças encenadas nestas sociedades negras eram de autoria do diretor, afrodescendente, Arthur Rocha5.

O subtítulo Lugares públicos, se repetiu em uma nova coluna, desta vez para tratar das regras de comportamento social de negros (as) nos bondes e templos da capital. Conforme observou Charles Monteiro (2012), em Porto Alegre, "desde 1873, bondes puxados a burros, da Carris de Ferro Porto-Alegrense percorriam as ruas do centro de Porto Alegre ligando o centro aos arraiais". Em 1906, começou-se a explorar o serviço de bondes elétricos que fez surgir uma nova cultura urbana ligada aos bondes e a iluminação do centro da cidade. Portanto, a ampliação dos espaços de sociabilidade na cidade configurava uma nova urbanidade para a qual se faziam necessárias posturas sociais específicas. A matéria advertia: "quando não se tem confiança na própria urbanidade, é melhor subtrair-se a frequência em certos lugares que frequentá-los e exibir uma triste figura". (O EXEMPLO, 14/04/1917, p. 1).

Referindo-se à conduta nos templos, a coluna prescrevia que, "o culto alheio devia ser estritamente respeitado" e que "quem assim não o fizer, passará de indelicado e pior educado" e recomendava: "respeite o culto alheio afim de que o nosso seja também

\footnotetext{
${ }^{4}$ A Floresta Aurora foi a primeira sociedade de negros fundada em Porto Alegre, em 31 de dezembro de 1872.

${ }^{5}$ Para detalhes sobre a vida e obra do diretor negro Arthur Rocha, conferir a tese de Isabel Silveira dos Santos (2015).
}

\begin{tabular}{|l|l|l|l|l|l|}
\hline Hist. Educ. (Online) & Porto Alegre & v. 22 & n. 54 & jan./abr. 2018 & p. 280-298
\end{tabular}


respeitado pelos outros". Neste ponto, observa-se o que já foi sublinhado por Guimarães (2002) e Braga (2015), que, no pós-abolição, o projeto de educação para os negros significava também, uma forma de rejeitar os estereótipos associados ao negro e à sua cultura, neste caso, uma alusão aos preconceitos contra as religiões afro-brasileiras, que, por um longo período, foram representadas negativamente, desrespeitadas e discriminadas. Nesta época, era comum que a polícia interrompesse o batuque e levasse as pessoas presentes para a delegacia.

Por outro lado, as recomendações da coluna Da Educação eram também no sentido do controle dos gestos e dos corpos. Conforme afirma Revel (1991, p. 6), "é sobre o corpo que as normas da civilidade se exerciam com maior rigor" e pode-se dizer também, os preceitos médico-higienistas, voltados à higiene do corpo. Daí, que esses dois discursos estavam combinados na coluna Da Educação, visando a produção de sujeitos civilizados e higiênicos nas primeiras décadas do século XIX. Na seção denominada "os maus hábitos", recomendava-se não "gesticular durante a conversa" e não "tapear nos ombros ou braços de outros" e afirmava-se:

O comedimento em todos os atos da vida de relações sociais é o imã que leva o indivíduo a ser estimado por todos. É mais lisonjeiro ser o indivíduo conhecido como acanhado, retraído, de falta de espírito comunicativo, que possuir o inverso destes predicados, com grande moléstia daqueles que sofrem 0 efeito de suas manifestações. (O EXEMPLO, Da Educação, 15/04/1917, p. 1).

Em geral, recomendava-se "o comedimento", ser "acanhado ou retraído", que era considerado melhor do que "gesticular e pronunciar frases gritando". O "meio termo" era sempre preferível e recomendável em todos os comportamentos. No que se refere ao corpo, hábitos relativos à higiene dos dentes e das unhas, também mereceram um olhar pedagógico por parte dos articulistas:

Quando no meio da palestra lembrar-se alguém de tirar do bolso um canivete ou palito e proceder a limpeza das unhas é um ato de má educação e um atentado a higiene pessoal. Espalitar os dentes posteriores abrindo a boca de maneira a poder alcançá-los é um ato indelicado sendo praticado na presença de outras pessoas. Acompanhar a espalitação dos dentes com estalos da língua ou expelir para todos os cantos os resíduos que se encontram entre os dentes é também uma indelicadeza que mui facilmente pode ser evitada atendendo a pessoa a uma ocasião oportuna para proceder a limpeza da boca. Também quem pretender fazer a limpeza das unhas procure o quarto e ali, livre das vistas alheias, corte e limpe as extremidades solida dos dedos. (O EXEMPLO, Da Educação, 15/04/1917, p. 1).

Também na coluna dedicada as visitas recomendações sobre como sentar-se e onde colocar as mãos eram meticulosamente descritas, apontando-se o que era e o que não era conveniente, exercendo-se e impondo-se um rigoroso controle sobre os gestos e valorizando-se a modéstia e a discrição como condutas recomendadas:

Sentados, temos também que observar certos preceitos, pois não estamos em casa sozinho e, por isso, não podemos dar ao corpo a comodidade que requer. Trançar as pernas ou colocar uma por cima da outra não é conveniente: inflecti-las de modo que originem movimentos contínuos, ringindo as botinas, também não é conveniente: fazer um joelho chocar-se de contra o outro, é ridículo: ocupar as mãos fazendo os polegares girarem como asas de moinho, ou cruzá-las na frente dos joelhos ou assentar-se em cima delas ou mete-las nos bolsos, não convém com os preceitos de boa educação. Recostar-se demasiadamente no espaldar da cadeira, 
espichar as pernas para frente ou abri-las desmesuradamente, deve ser evitado. Sentar-se modestamente servindo-se do espaldar como ponto de apoio e não encosto, conservando o tronco meio inclinado para frente em posição de quem escuta; mãos cruzadas sobre as coxas ou abertas sobre cada uma delas, entretêla com o leque, bolsa etc., discretamente: ter os pés juntos de maneira a não se distanciarem muito um do outro nem se afastarem demasiado dos pés do cômodo que nos serve de assento é a maneira mais própria e adaptável a qualquer gênero de visitas que fizermos. (O EXEMPLO, Da Educação, 20/05/1917, p. 1).

Nas colunas denominadas Da Comida em Geral, ensinavam-se as "regras de como comer" e comportar-se à mesa, que se tornou espaço central para o exercício das novas sociabilidades, e onde se recomendava o autocontrole do corpo por meio do apelo a higiene e a civilidade. Assim, os cuidados ao sentar-se à mesa incluíam: "lavar mãos, rosto e boca" em "uma previa e higiênica lavagem", "não firmar os cotovelos na borda da mesa", "desdobrar o guardanapo sobre o peito ou sobre o colo", "não farejar hircinamente as iguarias" e "se quiseres servir-te de pão, podes parti-lo com a mão em pequenos pedaços, porém nunca o porás na boca para arrancá-lo como quem tira um dente", e "quando pegares no copo, bebe devagar a pequenos goles e nunca a moda de quem lava a boca" e advertia-se: "lamber os dedos, a colher, o garfo e a faca, é indício certo de incivilidade e má educação". O correto era "comer com o maior asseio possível, procurando mesmo fazêlo com certa graça" e "para o asseio da boca deve-se usar do palito toda vez que for necessário, mas ninguém se exponha ao ridículo de andar de palito a boca fora da mesa, pois é uma falta grosseira de delicadeza e civilidade. (O EXEMPLO, Da Educação, 09/09/1917). Nestes excertos, observa-se a preocupação com a visibilidade dos gestos nos lugares sociais, que poderiam comprometer o caráter e o status do indivíduo e que, no caso dos negros (as), poderiam remeter as memórias do cativeiro e ao estigma de inferioridade.

$\mathrm{Na}$ coluna Da Educação, com o subtítulo As Visitas, as narrativas se referem também à aparência e os cuidados com o vestuário, considerados parte importante no intercâmbio social. Conforme Oliveira (2011), a partir da segunda metade do oitocentos, a sociedade que se desejava civilizada faria novas reivindicações para vestir seu próprio corpo, abandonando os critérios coloniais. Conforme o autor, "a nudez passou a ser castigada pelos médicos e moralistas que desejam corpos bem vestidos e bem cobertos" e passou a ser descrita como mau costume e má educação. (OLIVEIRA, 2011, p. 12). As narrativas explorando o cuidado com o vestuário ganharam força nos manuais de civilidade e também na coluna Da Educação, como se pode observar a seguir:

A pessoa que vai fazer uma visita, seja qual ela for, deve vestir-se descentemente e sem afetação. $O$ traje, impressão indireta com que despertamos a atenção do semelhante, deve ser consentâneo com o objeto da visita e na altura do mérito que nos merece a pessoa visitada. [...] O convencionalismo social impõe certas restrições à vontade individual, obrigando-a a uma certa norma de conduta, que por todos, fatalmente, vem a ser considerada como hábito geral e impassível de exceção. Como todo o hábito constitui lei, essa praxe torna-se uma lei natural obrigando a todos que vivem em comunhão social. (O EXEMPLO, Da Educação, 20/05/1917, p. 1).

Neste excerto, observa-se a determinação dos redatores do jornal na imposição de normas de conduta consideradas ideais para todos (as) e que deveriam ser incorporados por toda a sociedade. Conforme Elias (1989), no século XIX, as injunções e proibições sociais tornaram-se cada vez mais parte do indivíduo que será instado ao autocontrole de 
forma a se autorregular. Na coluna As Visitas, os redatores recomendavam para seus pares uma postura de vigilância e autocontrole no trajar quando fossem fazer uma visita: "muitas vezes, quando fazemos uma visita que resolvemos depois de estar na via pública, nem nos lembramos de vistoriar a compostura modesta ou exagerada de nosso trajar. [...] Por isso, cuidado, muito cuidado, com a maneira de trajar quando tencionar fazer uma visita". ( $O$ EXEMPLO, Da Educação, 20/05/1917, p. 1). Observa-se que o texto impunha um vestir comedido e modesto, evitando o exagero.

Também na coluna Nos bailes, pode-se observar novamente um discurso normativo, com recomendações sobre como comportar-se e como se vestir-se. Nesta seção, advertia-se: "não é só saber dançar, é necessário saber portar-se durante um baile, desde o seu início até a hora em dos últimos acordes da música", e continuava "admitida a dança como divertimento social, mister se faz que, a exemplo do que temos feito em relação a outras manifestações sociais, que suas regras de cortesia sejam convenientemente traçadas". (O EXEMPLO, Da Educação, 12/08/1917, p. 1).

Cynthia Veiga (2002), apropriando-se de Elias, afirma que o conceito de cortesia na Idade Média era usado pelos cortesãos como forma de marcar distinção social, em relação às pessoas rudes e camponesas. Possivelmente, também para os intelectuais negros que circulavam em torno do jornal $O$ Exemplo, as regras de cortesia operassem como marca de distinção, vinculadas à ideia de uma comunidade negra que precisava se reeducar no pós-abolição. Com esta intenção, recomendava-se como vestir-se devidamente para um baile de gala:

[...] traje preto, casaca ou smoking; camisa de peito duro com botões pretos, sapato de verniz e meias pretas de seda, chapéu alto. E, um momento: As luvas brancas ou pretas devem estar de acordo com a gravata, sempre da mesma cor. Não esqueça o lenço de seda nem o cartão de convite. (O EXEMPLO, Da Educação, 12/08/1917, p. 1).

Irene Santos (2010, p. 94), em seu estudo sobre a memória fotográfica dos territórios negros de Porto Alegre, relata que "eram inúmeros os salões de baile, nos vários territórios negros da cidade de Porto Alegre, onde os negros podiam dançar e ouvir boa música, livres do assédio da polícia e da crítica preconceituosa da vizinhança". Entre eles, o salão da Sociedade Floresta Aurora e o salão do Rui ou Sociedade Rui Barbosa, no coração do bairro conhecido como Colônia Africana, atualmente bairro Rio Branco. A autora destaca o depoimento de dona Zulmira, com 106 anos, que afirma:

[...] as pessoas andavam bem vestidas. Nos bailes, não iam de tênis e bermuda como agora. Antigamente não era essa desarrumação. Os homens, todos de fatiota, as mulheres, faziam roupas que sentavam bem no corpo, nada muito apertado. Meia de seda para quem podia comprar. Quem não podia, não ia ao baile. (SANTOS, 2010, p. 101).

O historiador Leo Spitzer (2001) salienta que a adoção de uma aparência formal entre negros no final do século XIX e início do XX, vestindo-se com distinção e incorporando a moda europeia, eram fatores chave para sua admissão e mobilidade social na sociedade branca.

Interessante observar-se também, nas regras relativas aos bailes, as referências à higiene, à saúde e à doença, como nos excertos que seguem: 
[...] sempre que se dançar, devemos colocar um lenço na mão para que o suor não se transmita a pessoa com quem dançamos, nem lhe nodoe as roupas no caso de se dançar levianamente com as mãos sujas de doces ou qualquer outra coisa. [...] todos nós sabemos que num simples apertar de mão muitas vezes se transmite moléstias a outrem. (O EXEMPLO, Da Educação, 09/09/1917, p. 1).

E, acrescentando-se: "não é muito delicado conversar durante a dança, pois com o esforço da respiração, as faces dos pares serão instantaneamente chicoteadas pelo hálito do palestrante". (O EXEMPLO, Da Educação, 09/09/1917, p. 1).

Portanto, no geral, as colunas $D a$ Educação produziram uma rede de prescrições, com base nos discursos de civilidade, médico-higienista e positivista, que deveriam tornase parte do cotidiano de negros (as), no esforço de modelar seus hábitos e "na tentativa de superar as visões preconceituosas que pairavam sobre seu comportamento, a fim de promover a integração social entre os grupos". (BRAGA, 2015, p. 93).

\title{
Prescrevendo comportamentos para maridos e esposas
}

O final do século XIX e início do século XX no Brasil é também o momento em que se passa a regulamentar com maior detalhe o papel das mulheres e dos homens na família e fora dela. No que se refere às mulheres, a ênfase era no papel da mulher como genitora e esposa exemplar. Joana Maria Pedro (1997, p. 298), destaca as peculiaridades deste cenário no Rio Grande do Sul, onde prevaleciam os ideais positivistas de Augusto Comte, propagados pelo Partido Republicano e expressos na Constituição Rio-Grandense de 1891. Para os positivistas, as mulheres seriam as "guardiãs da moral", desde que seguissem um modelo feminino socialmente adequado para a época: o de mulher submissa. A subordinação feminina estava relacionada, primeiramente, à figura paterna e, em segundo lugar, à do marido. Na mesma direção, naturalizava-se o amor feminino. As mulheres eram naturalmente mais amorosas e bondosas. É o que refere Joana Maria Pedro ao destacar as máximas do Centro Positivista de Porto Alegre:

\begin{abstract}
A mulher tem mais pureza que o homem. E tem também mais ternura, que é a máxima do altruísmo. Tem mais apego, mais veneração e mais bondade, isto é, mais amor. Instintos são estes de obediência, porque amar é obedecer, é preferir à vontade própria a vontade alheia; é gozar a felicidade de ver os outros felizes: é saborear o encanto de ver os outros satisfeitos. (PEDRO, 1997, p. 298).
\end{abstract}

De acordo com os propósitos positivistas, a mulher ideal deveria ser uma filha obediente, uma esposa dedicada, uma mãe exemplar e, quando pobre, trabalhadora virtuosa. (PEDRO, 1997). Tal pensamento, que se referia primeiramente às camadas médias e superiores da população gaúcha, também reverberava, em certa medida, nas mulheres das classes populares, que como trabalhadoras, deveriam ser honestas e organizadas e capazes de educar seus filhos. Uma matéria do jornal $O$ Exemplo descrevia que entre as obrigações da "esposa correta" estava não contrariar jamais seus esposos, "ser sincera em tudo, higiênica, carinhosa e dar-Ihes coisas boas para comer [...] uma esposa, desde o primeiro dia, deve estudar o seu marido, seus costumes, gostos e modos, para não the contrariar nunca". (O EXEMPLO, 05/03/1917, p. 4). Também a matéria intitulada "Arrependido de ter casado" reforçava as obrigações da esposa, que abrangiam desde os prazeres do marido até o progresso do universo: 
Uma esposa não é unicamente uma mulher para saciar os instintos amorosos do homem, é um ente de quem depende toda felicidade do seu marido e o futuro de seus filhos e aforando-se mais um pouco, é da mulher esposa que depende o progresso e o futuro do universo. Uma esposa sincera em tudo carinhosa, higiênica, virtuosa, bondosa e com a timidez própria de seu sexo, vale tanto como todos os tesouros da terra. (O EXEMPLO, 28/03/1916, p. 3).

Também o discurso higienista reforçava o papel da mulher como "rainha do lar" e na educação de seus filhos. Ela era a responsável por regular e "doutrinar" o comportamento dos pequenos.

Na direção e doutrinação do pequeno, a genitora tem no lar o papel proeminente por ser nele, onde a plenitude de sua autoridade se exercita de uma maneira mais nobre e respeitosa. Pelo papel desempenhado no lar pela mulher chegou o poeta dizer que a - mulher é uma rainha e que seu trono repousa no lar. Também à mulher por ser um espírito mais terno e complacente essa missão entregue aos seus desvelos é muito melhor exercida. (O EXEMPLO, 05/03/1916, p. 1).

Conforme afirma Marcus Carvalho, "a mulher, poderia reinar no lar, mas as leis eram feitas pelos homens" (2006, p. 185). O espaço privilegiado de atuação dos homens era o espaço público, no "trabalho externo", na tarefa de "provedor". No lar, a presença do homem era "nas horas de lazer", discurso que foi apropriado pelo jornal O Exemplo, como se observa no excerto que segue:

O homem habita a casa nas horas de lazer, onde o trabalho diário externo the concede tréguas. Não pode, como a mulher, observar atentamente as transmutações de caráter do pequeno avindas com o seu desenvolvimento físico. [...] a sociedade nada mais é que o conjunto de várias famílias; e, quem soube viver bem e respeitado no seio duma destas famílias saberá também adaptar-se no consórcio de todas elas reunidas. E o indivíduo que assim se acomodar no convívio de seus símiles será, sem dúvida nenhuma, um bom cidadão. (O EXEMPLO, 18/03/1917, p. 1).

Carvalho (2006) argumenta que a

[...] representação da boa esposa também era importante para a construção das noções de dignidade e honra masculinas. Do homem também era exigido um bom casamento. Envelhecer solteiro poderia significar pobreza, infertilidade ou homossexualismo. (p. 184).

O excerto que segue, da matéria intitulada Os 8 mandamentos do marido exemplar, afirmava os deveres e obrigações do marido e recomendava que as leitoras do jornal lessem em voz alta para seus maridos, explicitando o caráter pedagógico e normativo da coluna. Dos oito mandamentos, três tinham tom prescritivo e recomendavam ao esposo:

Trabalhar com alegria e confiança certo de que o esforço próprio é a escada mais segura pela vida. Acabado o trabalho na cidade, voltar diretamente para a casa, evitando relações inúteis de rua e despesas supérfluas. Almoçar e jantar sempre em casa, fugindo aos convites de refeições em restaurantes em companhia dos amigos ou conhecidos. (O EXEMPLO, 22/07/1917, p. 1).

Observa-se que o papel do homem no casamento era o de provedor e a ele pertencia o mundo do trabalho fora do lar, mas seu comportamento também era vigiado, cerceado e controlado. Os outros cinco mandamentos da matéria começavam todos com 
um "não". Conforme afirma Schwarcz (1997), ao referir-se ao Código do "Bom-Tom", "era uma quantidade de nãos", que deixavam claro "a característica cerceadora desse tipo de obra". (SCHWARCZ, 1997, p. 23). Também nas narrativas das colunas Da Educação a multiplicidade de "nãos" demonstrava o aspecto prescritivo, regulador e controlador de comportamentos que a educação de negros (as) assumiu nestas narrativas no jornal $O$ Exemplo.

\begin{abstract}
Não dar, nunca em casa aos criados, ordens contrárias as que os mesmos já haviam recebido da patroa, pois o enfraquecimento da autoridade desta é o começo da desordem do lar. Não discutir, em hipótese alguma, com a esposa na frente dos fâmulos ou de quem quer que seja. Não ter absolutamente segredos para com a esposa e não se considerar nunca diminuído em sua autoridade quando aconselhado por esta. Não deixar de todos os meses que for possível, pôr na Caixa Econômica ou num banco algum dinheiro, por menor que seja a importância, para que a urgência de uma despesa extraordinária não o colha de surpresa. Não ir se não às diversões em que possa levar a esposa. (O EXEMPLO, 22/07/1917, p. 1).
\end{abstract}

Vale destacar, que a partir da década de 1970, os estudos de gênero ganharam força e a teorização feminista provocou uma virada epistemológica no estudo dos comportamentos atribuídos aos homens e às mulheres. Joan Scott (1995, p. 85) mostrou que as persistentes desigualdades entre as mulheres e os homens não podiam ser explicadas com base, apenas, em diferenças sexuais, rejeitando o determinismo biológico e destacando o aspecto relacional entre homens e mulheres dentro de uma perspectiva sociocultural. Também Teresa de Lauretis (1994) contribuiu para desnaturalizar as diferenças sexuais entre homens e mulheres, sublinhando que não eram universais, tampouco essências existentes a priori nos seres humanos, mas frutos de relações históricas e sociais. (LAURETIS, 1994, p. 208). Essas pesquisadoras contribuíram para a desconstrução do argumento de que as diferenças biológicas justificavam papéis sociais pré-determinados, que homens e mulheres deveriam desempenhar na sociedade. Portanto, entende-se que os significados atribuídos à mulher e aos homens na coluna Da Educação foram produzidos a partir de representações hegemônicas, em torno de comportamentos considerados naquela época adequados à mulheres e homens. Dessa forma, o lugar social das mulheres era determinado em oposição ao lugar social dos homens. Esses binarismos foram reforçados em muitas instâncias culturais e contribuíram para legitimar relações desiguais entre os sexos, como parece ser o caso nas colunas Da Educação no jornal $O$ Exemplo.

Conforme observa Amanda Braga (2015, p. 90), o que se percebe é que a imprensa negra no início do século $X X$ "exercia uma espécie de vigilância social, a cobrar de seus seguidores um comportamento notável, que deveria ser próprio de sua classe" (ibidem). Contudo, essas proposições pedagógicas não se aplicavam aos negros e negras de maneira uniforme. Particularmente no caso das mulheres negras, grande parte continuava exercendo atividades subordinadas, como empregadas domésticas, cozinheiras, lavadeiras, doceiras e prostitutas. Portanto, o projeto de educação universal endossado por grande parte dos intelectuais negros do jornal $O$ Exemplo, não se destinava a todas as mulheres e homens negros, mas principalmente as camadas médias que buscavam ascensão social e integração na sociedade brasileira da época. 


\section{Considerações parciais}

Diante do exposto, o que se pretendeu conduzir com essa análise foi possibilitar a compreensão do potencial pedagógico da imprensa negra, particularmente do jornal $O$ Exemplo, por meio da análise das narrativas da coluna Da Educação. Como parte da renovação historiográfica que tem redimensionado a imprensa como fonte documental, buscou-se "superar a perspectiva limitada de identificar a imprensa como portadora dos "fatos" e da "verdade" (NEVES; MOREL; FERREIRA, 2006), mas considerá-la como produtora de representações e proposições pedagógicas que contribuíram na construção de subjetividades e identidades negras.

As narrativas normativas da coluna Da Educação, com base nos manuais de civilidade e nos discursos médico-higienista e positivista, pretenderam normatizar comportamentos e prescrever e ensinar condutas e hábitos considerados adequados às necessidades sociais de uma emergente classe média negra de Porto Alegre. Parece-nos, portanto, que "as pedagogias das boas maneiras" foram produzidas no sentido de formar cidadãos negros civilizados e higiênicos, mais bem preparados para o convívio social nos novos espaços urbanos de Porto Alegre e também visando promover a integração e ascensão social de negros e negras na sociedade branca.

Através da análise dos excertos do periódico $O$ Exemplo aqui apresentados foi possível observar-se também, que as estratégias educativas acionadas nas narrativas da coluna $\mathrm{Da}$ Educação se apropriaram de discursos que circulavam na cultura dominante, estrategicamente adaptando-os aos espaços de sociabilidade da comunidade negra. Por outro lado, essas "pedagogias das boas maneiras" também se constituíram como contra narrativas às visões preconceituosas que pairavam sobre o comportamento de negros (as), acenando com novas possibilidades de inserção social entre o final do século XIX e as primeiras décadas do século XX.

\section{Referências}

ALMEIDA, Giane Elisa Sales de; ALVES, Claudia Maria Costa. Educação escolar de mulheres negras: interdições históricas. Educação em Questão, Natal, UFRN, v. 41, n. 27, p. 81-106, jul./dez. 2011.

BASTOS, Maria Helena Câmara. Espelho de papel: a imprensa e a história da educação. In: ARAÚJO, José Carlos; GATTI JR., Décio (Orgs.). Novos temas em história da educação. Instituições escolares e educação na imprensa. Uberlândia: EDUFU; Campinas: Autores Associados, 2002.

BRAGA, Amanda. História da beleza negra no Brasil: discursos, corpos e práticas. São Paulo: EdUFSCar, 2015.

CAMOZZATO, Viviane Castro; CARVALHO, Rodrigo Saballa de; ANDRADE, Paula Deporte (Orgs.). Pedagogias culturais: a arte de produzir modos de ser e viver na contemporaneidade. Curitiba: Appris, 2016.

CARVALHO, Marcus J. M. A Imprensa na Formação do Mercado de Trabalho Feminino No Século XIX. In: NEVES, Lucia Maria Bastos; MOREL, Marco.; FERREIRA, Tania Maria Bessone (Orgs.). História e Imprensa: Representações Culturais e Práticas de Poder. Rio de Janeiro: DP\&A, 2006.

CECCHIN, Cristiane; CUNHA, Maria Teresa Santos. Tenha modos! Educação e Sociabilidades em Manuais de Civilidade e Etiqueta (1900-1960). In: SIMPÓSIO 
INTERNACIONAL PROCESSO CIVILIZADOR, X, 2007, Campinas. Anais... Campinas: Unicamp, 2007, p.1-11. Disponível em:

<http://www.uel.br/grupoestudo/processoscivilizadores/portugues/sitesanais/anais10/Artig os_PDF/Cristiane_Cecchin.pdf>. Acesso em: 11 out. 2016.

COSTA, Jurandir Freire. Ordem Médica e Norma Familiar. 2 ed. Rio de Janeiro: Graal, 1983.

CUNHA, Maria Teresa Santos. Os dizeres das regras: Um estudo sobre manuais de civilidade e etiqueta. Florianópolis: UDESC, 2005.

DOWNING, D. H. John. Mídia radical: rebeldia nas comunicações e movimentos sociais. 2 ed. São Paulo: Editora Senac, 2004.

ELIAS, Norbert. A Sociedade da Corte. Lisboa: Editorial Estampa, 1989.

FRANCO, Sérgio da Costa. Guia Histórico. Porto Alegre: Ed. da Universidade, UFRGS, 1988.

GONÇALVES NETO, Wenceslau. Imprensa, civilização e educação: Uberabinha (MG) no início do século XX. In: ARAÚJO, José Carlos de Souza; GATTI Jr., Décio (Orgs.). Novos temas em história da educação no Brasil. Instituições escolares e educação na imprensa. Uberlândia: EDUFU; Campinas: Autores Associados, 2002.

GUIMARÃES, Sérgio Alfredo. Classes, Raças e Democracia. São Paulo: Fundação de Apoio à Universidade de São Paulo: Ed. 34, 2002.

HALL, Stuart. Cultura e Representação. Rio de Janeiro: Ed. PUC-Rio, 2016.

LAURETIS, Teresa de. A Tecnologia do Gênero. In: HOLLANDA, Heloisa Buarque de (Org.). Tendências e Impasses - O Feminismo como Crítica da Cultura. Rio de Janeiro: Rocco, 1994. p. 206-242.

MAZINI, André. A história da imprensa no contexto da historiografia brasileira.

Comunicação \& Mercado, Dourados, MS, v. 01, n. 02, edição especial, p. 297-304, nov. 2012.

MELO, José Marques de. Gêneros e formatos jornalísticos: um modelo classificatório. Intercom - RBCC, São Paulo, v. 39, n. 1, p. 39-56, jan./abr. 2016.

MONTEIRO, Charles. Breve história de Porto Alegre. Porto Alegre: Editora da Cidade, 2012.

MÜLLER, Liane Susan. As contas do meu rosário são balas de artilharia: irmandade, jornal e associações negras em Porto Alegre. Porto Alegre: Pragmatha, 2013.

NEVES, NEVES, Lucia Maria Bastos; MOREL, Marco.; FERREIRA, Tania Maria Bessone (Orgs.). História e imprensa: representações culturais e práticas de poder. Rio de Janeiro: DP\&A: FAPERG, 2006.

OLIVEIRA, Iranilson Buriti de. Narrativas de civilidade: o discurso médico-higienista nos manuais pedagógicos do segundo império. In: SIMPÓSIO NACIONAL DE HISTÓRIA, XXVI, 2011, São Paulo. Anais... São Paulo: USP, 2011. p. 1-17. Disponível em: <http://www.snh2011.anpuh.org/resources/anais/14/1298989763_ARQUIVO_narrativascivilidade-texto.pdf $>$. Acesso em: 14 out. 2016.

PASQUINI, Adriana Salvaterra; TOLEDO, Cézar Alencar. Historiografia da educação: a imprensa enquanto fonte de investigação. Interfaces Científicas - Educação, Aracaju, v. 2, n. 3, p. 257-267, jun. 2014.

PEDRO, Joana Maria. Mulheres do Sul. In: DEL PRIORE, Mary (Org.). História das Mulheres no Brasil. São Paulo: Contexto, 1997. p. 278-321. 
REVEL, Jacques. Os usos da civilidade. In: ARIÈS, Philippe; DUBY, Georges (Orgs.). História da Vida Privada. v. 3. São Paulo: Companhia das Letras, 1991.

RODRIGUES, Divania Luiza; MARRONI, Paula Carolina Teixeira. A Civilidade como Pedagogia do Comportamento. In: ANPED SUL, IX, 2012, Caxias do Sul. Anais... Caxias do Sul: UCS, 2012. p. 1-14. Disponível em:

<http://www.portalanpedsul.com.br/admin/uploads/2012/Historia_da_Educacao/Trabalho/0 3_37_06_3068-6418-1-PB.pdf>. Acesso em: 13 out. 2016.

SANTOS, Irene (Org.). Colonos e Quilombolas: memória fotográfica das colônias africanas de Porto Alegre. Porto Alegre, 2010.

SANTOS, Isabel Silveira. Cultura teatral no Rio Grande do Sul: Raça, Identidade e Pedagogias. 2015. Tese (Doutorado em Educação) - Instituto de Filosofia e Ciências Humanas da Universidade Federal do Rio Grande do Sul - UFRGS, Porto Alegre, 2015.

SCHWARCZ, Lilia Moritz (Introdução). In: ROQUETTE, J. I. Código do Bom-Tom ou regras da civilidade e de bem viver no século XIX. São Paulo: Cia das Letras, 1997.

SCOTT, Joan. Gênero: uma categoria útil de análise histórica. Educação \& Realidade. Porto Alegre, v. 20, n. 2, p. 71-99, jul./dez. 1995.

SILVA, Tomaz Tadeu da. Documentos de identidade: uma introdução às teorias do currículo. 3 ed. Belo Horizonte: Autêntica Editora, 2014.

SPITZER, Leo. Vidas de Entremeio: assimilação e marginalização na Áustria, no Brasil e na África Ocidental, 1780-1945. Rio de Janeiro: EDUERJ, 2001.

STEPHANOU, Maria. Saúde, Higiene e Civilidade em Manuais. In: CONGRESSO BRASILEIRO DE HISTÓRIA DA EDUCAÇÃO, 3, 2004, Curitiba. Anais... Curitiba: Universitária Champagnat, 2004. p. 1-15. Disponível em:

<http://www.sbhe.org.br/novo/congressos/cbhe3/Documentos/Coord/Eixo4/486.pdf>.

Acesso em: 12 out. 2016.

VEIGA, Cynthia Greive. A escolarização como projeto de civilização. Revista Brasileira de Educação, n. 21, p. 90-170, set./out./dez. 2002.

ZUBARAN, Maria Angélica. História, Acervo e Protagonismo Negro no Jornal O Exemplo (1892-1930). In: SILVA, Fernanda Oliveira da; PERUSSATTO, Melina Kleinert; WEIMER, Rodrigo de Azevedo; SILVA, Sarah Amaral (Orgs.). Ciclo de debates sobre o jornal "O Exemplo": temas, problemas e perspectivas. Porto Alegre: Instituto Histórico e Geográfico do Rio Grande do Sul, 2016. p. 7-18.

MARIA ANGÉLICA ZUBARAN é professora na Universidade Luterana do Brasil, Doutora em História na State University of New York, Pós-doutorado no Birkbeck College, London University.

Endereço: Avenida Farroupilha, 8001- 92425-900 -Canoas/RS - Brasil.

E-mail: angelicazubaran@yahoo.com.br

JULIANA RIBEIRO DE VARGAS é professora na Universidade Luterana do Brasil, Doutora em Educação e Pós-doutoranda no Programa de Pós-Graduação em Educação e Ciências da Furg.

Endereço: Avenida Farroupilha, 8001- 92425-900 -Canoas/RS - Brasil.

E-mail: julivargas10@hotmail.com 
Recebido em 27 de novembro de 2016.

Aceito em 01 de março de 2017. 